\title{
$\square$ Comparison of regional 2D strain analysis to visual wall motion abnormality assessment in patients with non-ST elevation acute coronary syndrome
}

\section{Daniel Lovrić*, \\ Kristina Gašparović, Vlatka Rešković \\ Lukšić, \\ Marijan Pašalić, \\ Dejan Došen, \\ Jana Ljubas Maček, \\ Zvonimir Ostojić, \\ Marija Brestovac, \\ Jadranka Šeparović \\ Hanževački}

University of Zagreb School of Medicine, University Hospital Centre Zagreb, Zagreb,

Croatia
RECEIVED:

March 11, 2017

ACCEPTED:

April 6, 2017

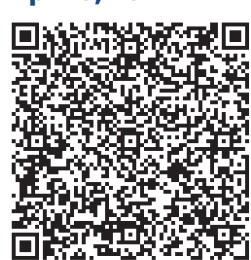

KEYWORDS: regional wall motion assessment, acute coronary syndrome, coronary stenosis localization, regional 2D strain.

CITATION: Cardiol Croat. 2017;12(4):119-120. | https://doi.org/10.15836/ccar2017.119

*ADDRESS FOR CORRESPONDENCE: Daniel Lovrić, Klinički bolnički centar Zagreb, Kišpatićeva 12, HR-10000 Zagreb, Croatia. / Phone: +385-91-4488-350 / E-mail: daniel@dlovric.net

ORCID: Daniel Lovrić, http://orcid.org/0000-0002-5052-6559 • Kristina Gašparović, http://orcid.org/0000-0002-1191-4831 Vlatka Rešković Lukšić , http://orcid.org/0000-0002-4721-3236 • Marijan Pašalić, http://orcid.org/0000-0002-3197-2190 Dejan Došen, http://orcid.org/0000-0002-2641-4768 • Jana Ljubas Maček, http://orcid.org/0000-0001-7171-2206 Zvonimir Ostojić, http://orcid.org/0000-0003-1762-9270 • Marija Brestovac, http://orcid.org/0000-0003-1542-2890 Jadranka Šeparović Hanževački, http://orcid.org/0000-0002-3437-6407

IIIIIIIIIIIIIIIIIIIIIIIIIIIIIIIIIIIIIIIIIIIIIIIIIIIIIIIIIIIIIIIIIIIIIIIIIIIIIIIIIIIIIIIIIIIIIIIIIIIIIIIIIIIIIIIIIIIIIIIII

Background: Visual assessment of regional wall motion abnormalities (RWMA) on echocardiography represents the current standard in assessing the impact of coronary artery disease (CAD) induced changes in myocardial contractility. Although it has been proven to predict long-term outcomes it has been hard to rely on in acute situations due to the patient dependent variance in image acquisition quality and interoperator variability. ${ }^{1-4}$ We hypothesized that regional 2DS assessment due to the evaluation of longitudinal shortening that is barely visible to the naked eye could potentially be more sensitive than visual RWMA assessment in detecting ischemia induced loss of contractility in non-ST elevation acute coronary syndrome (NSTE-ACS).

Methods: We performed a retrospective analysis of patients admitted through our Emergency Room to the Cardiology Department from January 2013 till December 2015 with the diagnosis of NSTE-ACS. Patients who did not undergo coronary angiography, patients with known prior coronary artery disease and patients who did not receive an echo in the 24 hours prior to angiography were excluded, as were the patients with images not adequate for 2D strain analysis. A total of 123 patients fulfilled the criteria and were included in the analysis and 4 different clinicians blinded to laboratory and ECG results performed 2DS analysis of global and regional 2D longitudinal peak systolic strain (LPSS) according to the 18-segment model prior to coronary angiography. Regional wall motion abnormalities (RWMA) as interpreted by the clinician performing the original echo exam were categorized according to the wall motion score guidelines.

Results: RWMA assessment shows good predictive power of coronary artery stenosis location in
TABLE 1. Regional visual wall motion assessment 2D longitudinal peak systolic strain values according to segments and location of coronary stenosis.

\begin{tabular}{lcc} 
Segment & $\begin{array}{c}\text { Lession } \\
\text { location }\end{array}$ & $\boldsymbol{P}$ \\
\hline APLAX Basal anteroseptum & LAD & 0.098 \\
\hline APLAX Mid anteroseptum & LAD & $<0.0001$ \\
\hline APLAX Apical anteroseptum & LAD & $<0.0001$ \\
\hline APLAX Apical inferolateral & LCx & $<0.0001$ \\
\hline APLAX Mid inferolateral & LCx & 0.04 \\
\hline APLAX Basal inferolateral & LCx & 0.01 \\
\hline A4C Basal inferoseptal & RCA & 0.087 \\
\hline A4C Mid inferoseptal & LAD & 0.1 \\
\hline A4C Apical inferoseptal & LAD & $<0.0001$ \\
\hline A4C Apical anterolateral & LAD & 0.003 \\
\hline A4C Mid anterolateral & LCx & 0.366 \\
\hline A4C Basal anterolateral & LCx & 0.015 \\
\hline A2C Basal inferior & RCA & 0.133 \\
\hline A2C Mid inferior & RCA & 0.722 \\
\hline A2C Apical inferior & LAD & 0.15 \\
\hline A2C Apical anterior & LAD & $<0.0001$ \\
\hline A2C Mid anterior & LAD & 0.027 \\
\hline A2C Basal anterior & LAD & 0.032 \\
\hline A $~$ & &
\end{tabular}

$L A D=$ left anterior descending coronary artery; $L C x=$ left circumflex coronary artery; RCA = right coronary artery; $\mathrm{APLAX}=$ Apical long axis view; $\mathrm{A} 4 \mathrm{C}=$ Apical four chamber view; $\mathrm{A} 2 \mathrm{C}=$ Apical two chamber view. 
LAD and LCx, but not in RCA (Table 1). However, LPSS was significantly more precise overall (mean sensitivity $75.6 \%$ vs $39.5 \%$, $\mathrm{P}<0.001)$. Statistically significant difference was present even after accounting for potentially confounding factors like arterial hypertension, smoking, alcohol, atrial fibrillation, valvular disease, age or prior medical therapy.

Conclusion: We have shown that a decrease in LPSS is significantly more accurate in detecting ischemia-induced loss of myocardial contractility than the visual assessment of RWMA in patients with NSTE-ACS. Our findings imply that 2DS should be employed as a supplementary tool during the echo assessment of patients with NSTE-ACS.

\section{LITERATURE IIIIIIIIIIIIIIIIIIIIIIIIIIIIIIIIIIIIIIIIIIIIIIIIIIIIIIIIIIIIIIIIIIIIIIIIIIIIIIIIIIIIIIIIIIIIIIIIIIIIIIIIIIIIIIIIIIIIIIIIIIIIIIII}

1. Cerqueira MD, Weissman NJ, Dilsizian V, Jacobs AK, Kaul S, Laskey WK, et al; American Heart Association Writing Group on Myocardial Segmentation and Registration for Cardiac Imaging. Standardized myocardial segmentation and nomenclature for tomographic imaging of the heart. A statement for healthcare professionals from the Cardiac Imaging Committee of the Council on Clinical Cardiology of the American Heart Association. Circulation. 2002 Jan 29;105(4):539-42. https://doi.org/10.1161/hc0402.102975

2. Sabia P, Afrookteh A, Touchstone DA, Keller MW, Esquivel L, Kaul S. Value of regional wall motion abnormality in the emergency room diagnosis of acute myocardial infarction. A prospective study using two-dimensional echocardiography. Circulation. 1991 Sep;84(3 Suppl):185-92. https://www.ncbi.nlm.nih.gov/pubmed/1884510

3. Montgomery DE, Puthumana JJ, Fox JM, Ogunyankin KO. Global longitudinal strain aids the detection of non-obstructive coronary artery disease in the resting echocardiogram. Eur Heart J Cardiovasc Imaging. 2012 Jul;13(7):579-87. https://doi.org/10.1093/ejechocard/jer282

4. Choi JO, Cho SW, Song YB, Cho SJ, Song BG, Lee SC, et al; Longitudinal 2D strain at rest predicts the presence of left main and three vessel coronary artery disease in patients without regional wall motion abnormality. Eur J Echocardiogr. 2009 Jul;10(5):695-701. https://doi.org/10.1093/ejechocard/jep041 